\title{
EL TEATRO DE ENTRECASA DE MANUEL PUIG: SUS CARTAS FAMILIARES DESDE UNA PERSPECTIVA QUEER
}

\author{
Ezequiel Lozano \\ Universidad de Buenos Aires y CONICET \\ lozanoezequiel@gmail.com
}

\section{RESUMEN / ABSTRACT}

El escrito toma como objeto las cartas familiares (publicadas) de Manuel Puig con el fin de pensar el género autobiográfico. Se describe el intercambio postal entre el escritor argentino y su familia [Puig, Manuel. Querida Familia: Tomo 1. Cartas europeas (1956-1962). Buenos Aires: Entropía, 2005; Querida Familia: Tomo 2. Cartas americanas. New York - Río (19631983). Buenos Aires: Entropía, 2006]. Las vivencias cotidianas puestas en palabras poética por Puig demuestran una restauración de la oralidad familiar, en especial, en su aspecto imitativo de la voz materna. El ensayo, a su vez, se apoya en la teoría queer para leer el ocultamiento de la sexualidad del escritor a los ojos de su familia.

Palabras clave: Puig, autobiografía, cartas, maternidad, queer.

The essay focuses on the conceptualization of family letters as a form of autobiography. We analyse the postal exchange between Manuel Puig and his family [Puig, Manuel. Querida Familia: Tomo 1. Cartas europeas (1956-1962). Buenos Aires: Entropía, 2005; Querida Familia: Tomo 2. Cartas americanas. New York - Río (1963-1983). Buenos Aires: Entropía, 2006]. The relationship with verbal poetry shows a framework that restores orality by creating the opportunity to glimpse that margin almost unrecoverable of the live event from everyday speech, specially in Manuel Puig voice and his mother. Also, we appeal to queer theory in order to read sexual invisibility into these materials.

KEY WORDS: Puig, autobiography, letters, maternity, queer. 


\section{“(...) catarata (cascada) de imágenes y ruidos familiares, como de living de entrecasa, al mismo tiempo traspasados por un sutil extrañamiento que los vuelca y vacía: vacuidad". \\ Néstor Perlongher}

\section{INTRODUCCIÓN}

Nuestro objeto de análisis es un tipo de escrito que presenta algunas particularidades especiales respecto del género autobiográfico ${ }^{1}$. No se trata de un texto escrito para ser publicado aunque sí para ser leído; ni tampoco es un escrito que intencionalmente quiera dar cuenta de la vida de su autor en un relato. Se trata de cartas: correspondencia privada enviada por Manuel Puig a su familia. Comienzan con la partida hacia Italia, a los 23 años del autor. Asimismo, es un intercambio del que solo accedemos a una de las partes, la del hijo (y hermano). Solo podemos reponer las cartas que su familia le envió por lo que escribió Manuel en las suyas. A su vez no se trata, tampoco, de una fuente primaria sino que el acceso que tenemos al material está mediado por la compilación, selección y recorte que hizo Graciela Goldchluk para los tomos que publicó la editorial Entropía. La compiladora agrupó las numerosas cartas en tres partes que organizó según su procedencia: las europeas (19561962), las provenientes de New York (1963-1967) y las últimas, desde Río de Janeiro (1980-1983). De modo que estas salvedades son parte del recorrido dado previamente al que intentaremos delinear en este escrito.

Pretendemos analizar algunos de los elementos presentes en esta correspondencia para poder visualizar las estrategias mediante las cuales Manuel Puig se narró a sí mismo ante su familia. El propósito es poder acercarnos más a este autor y a su intencionalidad creadora; pero, nos alejamos de una búsqueda de justificativos biográficos para explicar su obra. Creemos que las obras hablan por sí mismas y entre sí; y, al mismo tiempo, que podemos conocer la intencionalidad poética y política de Puig entendiendo los mecanismos mediante los cuales construyó una imagen de sí

Este trabajo se elaboró a partir de los materiales propuestos por la Dra. Nora Domínguez para su seminario de doctorado "Formas autobiográficas. Nuevas aproximaciones teórico-críticas y ficcionales", dictado en la Facultad de Filosofía y Letras de la Universidad de Buenos Aires durante el año 2010. 
para los suyos. Fundamentamos esta búsqueda de estrategias en la afirmación de Leonor Arfuch, quien sostuvo cuál era su interés al estudiar los dilemas de la subjetividad contemporánea:

(...) no es tanto el "contenido" del relato por sí mismo (...) sino, precisamente, las estrategias-ficcionales- de auto-representación lo que importa. No tanto la "verdad" de lo ocurrido sino su construcción narrativa, los modos de nombrar(se) en el relato, el vaivén de la vivencia o el recuerdo, el punto de la mirada, lo dejado en la sombra... en definitiva, qué historia (cuál de ellas) cuenta alguien de sí mismo o de otro $y o$. Y es esa cualidad autorreflexiva, ese camino de narración, el que será, en definitiva, significante (60).

¿Qué estrategias eligió Puig para mostrarse a los suyos? ¿Qué deja en la sombra? ¿Qué contenidos se reiteran carta a carta a plena luz? Claro que la develación de estos interrogantes implica zambullirnos en ese mundo privado de la correspondencia personal. Sylvia Saítta, que reseñó el tomo I compilado por Goldchluk, concluyó sobre este particular:

Si bien es más que deseable que la labor de este equipo de investigación continúe para que, en los próximos años, todos los lectores puedan acceder a los archivos completos de Puig, las preguntas que dicha empresa conlleva quedan abiertas: cuáles son los límites entre lo público y lo privado; cómo no atravesar la frontera -a veces invisible- entre la rigurosidad del investigador y el placer del voyeur (Saítta s/d).

Esta duda nos parece legítima aunque hoy, varios años después de que el libro saliera a luz, no podemos anclarnos en ella puesto que esa privacidad se transformó en algo público y con autorización expresa (y colaboración cercana) de los propios familiares de $\mathrm{Manuel}^{2}$.

2 El hermano de Manuel, Carlos, en una entrevista cuenta: "Para mí todas las cartas entraban en la esfera de lo privado, pero Graciela Goldchluk me pidió si podía leer el material. Y como es una persona que yo respeto mucho le di a leer algo. Y ella me convenció de la publicación porque eran cartas literarias y porque en ellas aparecía un escritor en formación" (Friera, Aquellas s/d). 


\section{CARTAS QUE VIENEN Y VAN}

Correspondencia: género afín al autobiográfico que fue parte de la génesis de éste. Por esto José Amícola señala un recorrido histórico donde señala que “ $(. .$.$) la edición de correspondencias cunde en Europa a partir de 1600,$ la redacción de memorias se expande a partir de 1700 y la publicación de diarios íntimos a partir de 1800" (20). También Leonor Arfuch nos aporta un dato similar al señalar, siguiendo a Habermas, al siglo XVIII como el del intercambio epistolar. La autora enmarca ese dato en un cambio de la subjetividad en el que las y los lectores encontraban un nuevo tema de ilustración en la representación de sí mismos en sus costumbres cotidianas (Arfuch 40). Así, a mediados de siglo XX, la correspondencia continuaba con ese despliegue de la subjetividad.

El primer tomo de Querida Familia se inicia con una carta desde el barco rumbo al primer puerto en Brasil, el día 30 de julio de 1956. Las cartas se suceden hasta el viernes 26 de octubre de 1962 cuando Manuel Puig dio comienzo a un viaje de regreso hacia Buenos Aires. Allí culmina el tomo I. La compilación organiza las cartas por años. Dentro de este primer tomo hay una pausa en el intercambio entre la carta desde Nazareth del 4 de noviembre de 1959 y la del 25 de febrero de 1961 desde Río de Janeiro. Esto se debe a una estadía de Puig en Buenos Aires durante 1960. El segundo tomo arranca con la carta fechada el día lunes 18 de febrero de 1963 desde New York y se cierra con la del miércoles 23 de noviembre de 1983 desde París. Hay una pausa de muchos años (1968-1979³). Para el desarrollo del trabajo elegimos citar estas fuentes por sus fechas de emisión dado que a pesar de su división en partes constituyen un único cuerpo de materiales ${ }^{4}$.

Manuel Puig encabezó estas cartas con un reiterado "Querida Familia" (de ahí el título editorial de las mismas) y las firmó con un apodo familiar "Coco_". Algunas veces ese encabezado tiene modificaciones como: "Queridísima familia" (24/08/56), "Gente querida" (16/06/57), "Querida gente" (14/12/57), "Familia querida" (23/12/57 y 02/02/58), "Dear family" (24/03/58, desde Londres), "Cara familia" (05/08/58; 08, 18, y 22 de septiembre de 1958; 31/03/59), "Querida family” (14/12/63). En ocasiones más excepcionales se

\footnotetext{
Período en el que el escritor se instaló algunos años en Buenos Aires y a la vez se tuvo que exiliar amenazado por la Triple A.

Así las cartas fechadas entre el 30/07/56 y el 26/10/62 corresponden al primer tomo; $\mathrm{y}$, aquellas emitidas entre el 18/02/63 y el 23/11/83 se pueden consultar en el segundo tomo.
} 
dirige particularmente a su hermano: "Querido Carlitos" (18-01-58); o a su padre: "Querido papá" (12/10/63; 25/06/66); o a ambos: "Queridos papá y Chino 5" (13/09/64; y 26/09/64); o a su madre: "Querida mamá" (12-06-61; 14-05-62; 17-07-62; 16/02/67; 18/02/67; y 21/02/67), "Buschiazzo ${ }^{6}$ ve!!!!" (11/08/63).

Por su lado, la firma es más constante excepto en los casos que detallamos: "Manuel" (04/03/81); "Giovanni (así le firmo a Luigi)" (22/12/63); y otras donde aparece el humor aplicado sobre sí mismo. Por ejemplo: "Coco (fermentado $7100 \%$ )" (14-11-57), "Coco_ (casi veinticinco abriles) povramé 8 ",

$\mathrm{Si}$, como señala Derrida, se escribe para comunicar algo a los ausentes, el caso de estas cartas es testimonio de una forma socialmente aceptada de traer al presente a aquellos seres cercanos con quienes se comparte el mismo tiempo pero en espacios distantes. Y la correspondencia cae dentro de las reglas generales de toda escritura; así, el signo escrito es una "marca que permanece" cuya fuerza rompe con el contexto de su inscripción y se separa (Derrida, Firma 358). La firma de Puig como Coco da cuenta de que él, como signatario, estuvo allí; en un ahora (el momento de la lectura) en que su no-presencia empírica es patente. La rúbrica señala "su haber estado presente en un ahora pasado, que será todavía una ahora futuro" (Derrida, Firma 370). Del mismo modo, las fechas impresas en cada carta señalando un tiempo y un espacio determinados son parte extensivas de esa misma firma. Ya lo dijo en Otobiografías el mismo Derrida: Datar es firmar.

Las cartas dan cuenta de los aspectos más cotidianos de la vida diaria en cada lugar en el que Manuel se establece temporalmente9. El lenguaje compartido por el escritor y su familia es afectuoso, cercano, y plagado de guiños y humor. Se suceden intercambios de materiales y hay una constante alusión a las dilaciones en la recepción de los sobres o de los problemas vinculados con el correo. Las cartas son generalmente minuciosas y extensas.

\footnotetext{
"Chino": apodo de su hermano Carlos. También lo llamará "Gato".

Chiste dirigido a su madre en relación con la actriz argentina María Esther Buschiazzo, actriz melodramática, prototipo de la madre sufriente.

"Fermento" expresión familiar para expresar un estado anímico alterado.

"pobre de mí" en el dialecto rural de Parma (usado con asiduidad para la comunicación interna de la familia Puig-Delledonne)

El intercambio epistolar de Manuel con su familia no era nuevo en su vida. Ya en su etapa de pupilo, Manuel había compartido cartas diarias con sus padres. Así lo referencia en la carta del sábado 4 de diciembre de 1965 .
} 
Los detalles tienen que ver con: el lugar que ocupa la ropa y la moda en su vida; la descripción de las comidas de cada sitio, su mirada sobre los lugares con sus paisajes y costumbres; su relación con el trabajo, etc. Manuel reclama con enojo cuando su hermano Carlos solo le escribe unas pocas líneas ${ }^{10}$. Exige lo mismo que da (que es aquello que le da su madre a él): detalles de los sucesos diarios con esa lupa mordaz y enfocada en ciertos aspectos como el buen vestir, las costumbres sociales, los trámites administrativos o la recreación cultural. A veces aparecen comentarios políticos. Muchas ocasiones se narran las peripecias para ingresar al mundo laboral del mismo modo que sus intentos por ingresar al mundo laboral como escritor o cineasta.

\section{QUERIDA MAMÁ...}

“(...) Voz de mujer, lengua de mujer, decir menor, un entretejido de "lugares comunes" -trama de linaza, estraza strassdeja sentir, como al trasluz, la fina agudeza de la vocecilla impertinente, dejando dicho lo que no decir".

Néstor Perlongher

Ahora bien, aunque en el encabezado predomine ese genérico "Querida familia", la comunicación se dirige principalmente a su madre ${ }^{11}$. De algún modo las cartas dan cuenta de un diálogo constante y fluido donde madre e hijo comparten los mismos criterios de observación de la realidad y lo ponen en palabras de modo semejante. La vía de comunicación con su padre y su hermano Carlos está mediada por la voz materna. Se reitera en varias cartas el pedido hacia los otros dos varones de la familia para que también le escriban. Las referencias a Carlitos y al padre se expresan en tercera persona a diferencia de las oraciones dirigidas a la madre. Por ejemplo: "Felicitaciones a Carlitos

10 El hermano de Manuel, Carlos, en una entrevista cuenta que "Recibir las cartas semanales de Manuel era un lujo para nosotros. A mí me pedía que le escribiera, pero después de leer esas maravillas yo me preguntaba qué le podía mandar, cómo escribir después de esas cartas" (Friera, Aquellas s/d).

11 Ver, por ejemplo, las interrupciones de la carta del 8 de septiembre de 1956 (apartado del jueves 13) donde se suceden encargues para su madre. A continuación de nuestro escrito se sucederán más casos. 
por la medalla" (05-12-56) o "quiero que me manden urgentísimo (...) los 20.000 del regalo que me hizo papá" (09-07-61); a diferencia del modo directo en que se comunica con la madre "(...) contame mamá cuánto duró. También contame si dieron la obra (...)" (17-07-61). A la vez es evidente que las pocas veces que decide comunicarse "en privado" con su hermano o su padre, lo hace concretamente en cartas dirigidas a la dirección de la fábrica de su padre o bien aclarando que una carta que se adjunta a la familiar es solo para su hermano $\operatorname{Carlos}^{12}$. De algún modo podemos observar que no hay "privacidad" con su madre sino que ella, en representación de la familia, dialoga con su hijo. Hay una profunda intimidad pero sabida y compartida con los demás integrantes del núcleo familiar. Se habla en privado por fuera de la madre.

Esta primera observación no es novedosa para la obra literaria de Puig. Ya César Aira en "El Sultán", haciendo referencia a novelas como Sangre de amor correspondido (1982) y Cae la noche tropical (1988), afirmó: "La madre es la historia, y transmite un estilo, y no es ni hace otra cosa. Puig fue el poeta de la maternidad. Por ser el hombre-madre fue el hombre-historia y el hombre-estilo" (28). Y, a propósito del estilo se explayó afirmando: "Una voz tiene estilo en función de su historia familiar. Antes de la voz está el gesto con que la voz se propone, y eso es lo que da la madre. El hijo imita sin saberlo (...) Pero la muerte es una cazadora ciega (...) en Puig historia y estilo son lo mismo" (28). Manuel no solo habla con su madre sino que la imita. Reproduce sus modos de decir y su necesidad de diálogo a la distancia. Las cartas van y vienen entre madre e hijo quienes comparten un universo común tanto familiar como cultural.

Tal es el nivel de elaboración del lenguaje interno de esta familia que la editorial Entropía le dedica un glosario a cada tomo donde se aclaran los términos que aparecen con asiduidad en las cartas. Fundamentalmente, cada glosario se dedica a traer luz a todo un bagaje de vocabulario que proviene de expresiones del dialecto rural que se hablaba en la zona de Parma-Piacenza; además se explicitan algunos términos italianos escritos a la española por Manuel. Este bagaje de expresiones es la herencia lingüística de la rama materna de la familia del escritor (Delledonne). Nuevamente la madre. Manuel Puig habla la lengua de la madre para comunicarse con su familia. Y habla con ella en un léxico compartido, mamado desde la cuna. 
Hay un estilo comunicacional marcado desde la primera carta. La historia de la familia de Puig está presente en un lenguaje particular cargado de un humor corrosivo junto a un afecto profundo y un cuidado por el/la otro/a. Así, los retos en tono humorístico se repiten durante la correspondencia. Por ejemplo: "Mamá: ¿no te da vergüenza hablar de emplearte? La suerte te puede castigar si te hacés la viva de ese modo" (12-06-61); o bien: "Y cada vez que veo las fotos de Genzano cómo te fuiste hecha una zaparrastrosa con todas las cosas que tenés, te daría en la cabeza con el bolsito que te compré en Papeete, vieja malvada, y te daría un latigazo con el collar que te compré esta mañana" (10/03/65). Así también los apodos ${ }^{13}$ de la madre a lo largo de las sucesivas cartas fueron variando. Algunos de los sobrenombres con los que llama a su madre a lo largo de estos años son: "Malisita", "Mamún", "Sra. de Puig", "Marialena", "Carola Lorenzini 14" "Buschiazzo"15", "María Esther ${ }^{16 ", ~ " B e t t e ~}{ }^{17 "}$.

El último apodo de la lista refiere a Bette Davis, claro. Por eso es curiosa la observación que hizo el escritor Jaime Manrique cuando redactó su propia autobiografía. En ésta, donde su vínculo de "hija" con Puig se describe en un capítulo entero, al dar cuenta de la fisonomía de Manuel hace también referencia a esta actriz del cine clásico de Hollywood para describirlo. Dice:

En persona resultó ser más teatral que Garbo: tenía los mismos gestos operísticos. Como los de Garbo, sus ojos eran una herramienta, un arma, órganos no sólo para ver sino para expresar lo que veía. Igual que la gran diva, elevaba la ceja (la izquierda) para indicar dolor, desdén, desesperación. La ceja era una cortina que subía o bajaba para resaltar unos ojos vivos encendidos, ojos que podían transmitirte su calidez o que podían hacerte desfallecer por su frialdad. Tenía

13 A propósito del humor: es recurrente este efecto logrado con el recurso de apodar a su padre, hermano y madre en la carta del 18 de abril de 1963. Los nombra con diferentes apodos a lo largo de la misma: "Chino, pendejo salvaje", "papún", etc.

14 En referencia a una famosa aviadora argentina. Aparece en la carta del 21/12/65.

15 Chiste dirigido a su madre en relación con la actriz argentina María Esther Buschiazzo, actriz melodramática, prototipo de la madre sufriente.

16 Ver nota anterior.

17 Comienza este chiste en la carta del 01/09/63 cuando escribió: "Bueno, me parece que en vez de Buschiazzo habrá que llamarte BETTE "La loba". Pero tarada no te conviene por que la Buschiazzo se la manda de buena y todos la tratan bien mientras que la Bette mandonea pero al final se queda sola". 
lo que en algunos círculos se conoce como "ojos de Bette Davis"” (Manrique 72).

No creemos que sea casual esta analogía que hace su alumno, quien lo conoció en sus últimos años. No es casual que nombre a Garbo y a Davis para describir la femineidad de Puig; ni que Bette sea descripta como la mirada que porta Manuel ya que lo que se observa en las cartas es que se detiene en detalles similares a los que su madre haría si estuviese en su lugar. Manuel llamaba Bette a su madre; su "hija" lo describe a Manuel con esa mirada. Lo bueno de una comunicación efectiva.

Madre e hijo amamantándose mediante cartas a la distancia. Una comunicación afectiva sostenida en el tiempo allende las diferencias de espacio. Un vínculo que los religa. Hilo blanco que los conecta de modo invisible. "Esto es por qué, cómo, quién, lo que, escribo: la leche. El alimento fuerte. La escritura también, es leche. Doy de mamar. Y como todas las que amamantan, soy amamantada. Una sonrisa me alimenta. Madre soy hija: si me sonríes, me das de mamar, soy tu hija. Bondades de los buenos intercambios" (Cixous 27). Así, tomando estas palabras de Helene Cixous, podemos imaginar la lactancia manifestada en esa escritura íntima compartida entre ambos. Un buen intercambio que continúa las anteriores horas compartidas. Un diálogo iniciado 9 meses antes del nacimiento de Manuel que se despliega, durante años, en papel.

Las cartas se suceden a través de múltiples viajes pero la literatura de Puig, y por momentos sus cartas, expresan un deseo nunca olvidado de regresar al origen, volver al vientre ( $¡$ esos recuerdos del pasado!). En los primeros años de alejamiento de su familia, las cartas muestran menos nostalgia que en las de la época en New York. El hecho de extrañar a su familia, que en aquellas primeras cartas no se hacía tan presente, se reitera con frecuencia en la segunda etapa de viajes que se inicia cuando se establece en Estados Unidos. Sobre este punto es interesante el relato de un sueño que aparece en la carta del sábado 14 de diciembre de1963:

La otra mañana fue el colmo: me despertó la radio como de costumbre, eran las 8:30 y oigo que empieza justo un programa de canciones de Cole Porter y me volví a quedar dormido pero entre sueños seguía oyendo la música y soñaba que las comentaba con mamá, pieza por pieza, hasta que terminó el programa a las 9 y recién me desperté y me encontré que estaba Richmond Hill (14/12/63). 
En este sentido las imágenes de cercanía siempre aparecen vinculadas con la figura materna, no así con los otros varones de la casa. De modo que esa diferencia yo/tú entre madre e hijo se torna muchas veces una comunicación especular, un enunciado de un yo para otro yo que lo duplica. Dos que se miran al espejo donde vuelven a ser uno ${ }^{18}$.

Otro ejemplo singular. Hay una carta con características especiales: es la del domingo 13 de agosto de 1961. Está encabezada por un "querida mamá" pero la firma no es solo la de Coco. Dos familiares llegaron a Roma de paseo y están, junto a Manuel, almorzando en una trattoría. Por eso se explayan en estas "líneas en conjunto" que, para ser exactos, son fragmentos diferenciados cada uno con una firma. Así, luego del encabezado con el que Manuel abre la carta, María escribe un "Querida María Elena" y narra lo compartido entre los tres en un lenguaje absolutamente familiar: "Te manda el Coco con nosotras dos preciosidades de vestidos (...)" y con un humor compartido: "Sí Arieta. Chupame la camiseta como no tengo camiseta chúpame la cola". Sigue a esta un párrafo más escueto de La Negra, con idéntico encabezado que el de María, donde elogia a Manuel: "tienes un hijo que es un tesoro y que jamás olvidaré el cariño y las atenciones que nos ha dispensado". Luego la carta la continúa Manuel ya cuando las dos visitantes partieron hacia Madrid.

Esta carta nos parece destacable porque por un lado aparece "la madre" como "María Elena". Su nombre propio es repuesto por fuera del rol materno. Y por otra parte, Manuel es narrado por otras voces para su madre. De algún modo las atenciones que les brinda a sus familiares están hechas para su madre que las recibe a la distancia. El lenguaje y humor de María dan cuenta, a su vez, de que muchos de los guiños lingüísticos y cómicos de la comunicación interna eran propios de la familia toda y no exclusivos de Manuel y su mamá.

18 Hacemos esta observación basándonos en el análisis que hizo Sylvia Molloy (de quien se habla más adelante en este escrito) cuando argumentó: "Muchos de estos poemas se dirigen a una segunda persona: una madre, una hermana, una musa, una amante. Con frecuencia, sin embargo, nos enfrentamos a actos interlocutorios fingidos que establecen la ilusión de una relación "yo/tu" que gradualmente se desintegra hasta perderse, como en un mosaico, en un sujeto de enunciación plural. El "yo" convoca a una segunda persona que es reflejo o contaminación del "yo" (...). El texto todo se vuelve acto especular, enunciado hacia una segunda persona que duplica al "yo", como sucede en tantos poemas de Pizarnik" (Molloy 81). 
Del mismo modo el hijo le comparte a la madre más voces otras sobre ella. En algunos momentos cita lo que algún amigo le dijo después de leer alguna de las cartas que su madre le envió y Manuel le compartió; o bien, como en el ejemplo que aquí traemos, comparte con ella en su escritura lo que un amigo cercano -que compartió parte de un viaje con la madre de Manuel- le escribiera: "Recibí carta de Mario, bastante animado, no sé de dónde le vienen los ánimos, qué plato, me dice "Male es encantadora al extremo, es una madre-joya" " $(28 / 10 / 66)$.

Este vínculo cercano con su madre será crucial incluso en los tópicos de la escritura de Manuel. Beatriz Sarlo es una de las críticas que describe esta situación en la primera novela del autor: "Escribió a su madre en Mita La traición de Rita Hayworth y luego escribió la literatura que le agradaría a Mita" (Pornografía 465). Así, no solo las cartas son la vía de diálogo con la madre sino también sus obras. El hijo manda desde los primeros escritos versiones preliminares a su familia esperando una devolución de los mismos. Incluso se defiende ante posibles heridas de la sensibilidad por trabajar con un imaginario propio de la familia en el contexto de General Villegas (ciudad natal del escritor).

Así como reflexionó sobre el rol de la mujer en la sociedad a través de su literatura, también lo hace en las cartas. Aquí un ejemplo particular sobre el rol de la madre y sus cambios: "Me escribió María, dice que la nena de Jorge es preciosa ¡qué plato, casi ni la va a cuidar de los muchachos! Eso va a ser fenomenal, aunque dentro de quince años yo creo que las madres van a servir las "píldoras" en la mesa, junto con la sal, el aceite, la soda y el puchero ¿no? Mamá, andá a verla y me contás" (01/12/66). Tan cercana es la relación que en 1983 la madre se muda al barrio de Leblon para vivir cerca de Manuel.

\section{A PROPÓSITO DE LA AUTOBIOGRAFÍA}

La correspondencia privada convertida luego en libro se edita desde hace siglos. Obviamente tiene un carácter autobiográfico a pesar de no ser un texto pleno de la autobiografía como género. Por todo esto queremos reflexionar sobre las concepciones acerca de la autobiografía para poder pensar luego el caso particular que aquí abordamos.

Paul de Man reflexionó sobre la figura retórica de la prosopopeya (convocar a los ausentes). Así, establece un análisis importante sobre el yo. Como explica Nora Catelli al momento de comenzar a narrar aparecen, según De Man, dos 
sujetos: el que ocupa el lugar de lo informe y otro que se posiciona en el sitio de la máscara que desfigura. Por eso este autor pudo concluir su artículo $L a$ autobiografía como desfiguración afirmando:

En cuanto entendemos que la función retórica de la prosopopeya consiste en dar voz o rostro por medio del lenguaje, comprendemos también que de lo que estamos privados no es de vida, sino de la forma y el sentido de un mundo que solo nos es accesible a través de la vía despojadora del entendimiento. La muerte es un nombre que damos a un apuro lingüístico, y la restauración de la vida mortal por medio de la autobiografía (la prosopopeya del nombre y de la voz) desposee y desfigura en la misma medida en que restaura. La autobiografía vela una desfiguración de la mente por ella misma causada (De Man 118).

Este intelectual deconstructivista puso en cuestión, además, si lo autobiográfico era o no un género. Loureiro le criticó el despojo de su teoría y afirmó que toda autobiografía se dirige a alguien. Para este teórico es un acto retórico y ético. Por su parte Lejeune, enmarcado en la Teoría de la Recepción, señaló la reciprocidad entre autor y lector y definió a la autobiografía como un relato referencial; el cual se define a nivel global como "un modo de lectura tanto como un tipo de escritura, es un efecto contractual que varía históricamente" (60). José Amícola, por su parte, recuerda que Lejeune con su fórmula del "pacto autobiográfico" trató de afrontar las dificultades para diferenciar la autobiografía de la novela "apelando a una entidad extratextual del lector que venía teniendo cada vez más relieve en la teoría crítica" (25). Los críticos de Lejeune señalaron que en su teoría la referencialidad a un autor como persona real extratextual simplifica una figura problemática como es la del Autor. Por eso Nicolás Rosa en 1990 la retomó para discutirle esto a partir de la noción del "Yo" donde lo autobiográfico explicita un proceso de autoanálisis en el cual el hecho de contar, ya de por sí, conlleva a escindir la propia personalidad.

Tomando el concepto desde la traducción castellana de una obra de Sylvia Molloy de 1991, Amícola definió a la autofiguración como "aquella forma de autorrepresentación que aparezca en los escritos autobiográficos de un autor, complementando, afianzando o recomponiendo la imagen propia que ese individuo ha llegado a labrarse dentro del ámbito en que su texto viene a insertarse" (14). Haciendo un raccontto histórico, este investigador pudo sostener que: 
En efecto, lo autobiográfico y las narrativas del yo (...) van a tomar lentamente una particular forma literaria a medida que crezca el individualismo burgués dentro de la tradición europea. Sin embargo, los autores varones de relatos autobiográficos utilizarán esas convenciones -convertidas lentamente en leyes de género "literario"-para diversos fines. Esa diversidad sitúa a los textos en marcos que necesariamente se encuentran en campos culturales históricamente muy diferentes (Amícola 15).

Una de las constantes que este pensador observa es la ausencia de descripciones del cuerpo del autobiógrafo, en especial si se trata de un varón (123). Por eso en su teoría el cuerpo tendrá un valor importante. Específicamente, en el caso de Puig que estamos abordando, no se evidencia esta situación. Muy por el contrario, en las cartas la autopercepción de su corporalidad es narrada con asiduidad ${ }^{19}$.

La investigadora española Genara Pulido Tirado diferencia textos donde: a) el yo emerge de manera directa o su presencia es de primer grado, b) el yo emerge como un espacio intermedio; o bien c) él emerge disfrazado. Los ejemplos característicos del segundo tipo son las memorias y del tercero las novelas autobiográficas. Es en el primer tipo donde la vastedad de los ejemplos es mayor: autobiografías en general, confesiones, correspondencias y

19 Aquí listamos algunos ejemplos de diferentes referencias a su propio cuerpo en las cartas: "Se me juntó la soledad con un poco de trastorno de estómago debido al exceso de sol (lo de siempre). Durante un día y medio comí liviano y se me pasó lo más bien" (08/09/56); "Estoy gordo, el pelo corto, mi cara es una luna llena" (27/02/57); “(...) estoy pesando 71" (05/11/57); "Le tuve que correr el botón del cuello a dos camisas, con eso está dicho todo. La macana es que con la pasta en Italia crié un poco de panza y pese a que todas las mañanas hago gimnasia no desaparece; a la vuelta de aquí hay una pileta cubierta municipal (recién la descubrí el otro día) trataré de ir algún día, pueda ser que con el pataleo queme esa grasa hija de puta. Si no quién los aguanta a ustedes cuando vuelva, entre las entradas del pelo (creo que aquí no se me cae en París), el caminar del abuelo, las bolsas incipientes en los ojos, la joroba y la panza!!!!! Bueno, no se asusten que no es para tanto" (24/03/58); "En las primeras semanas me parece que rebajé algo por tanto traqueteo pero ahora ya he aumentado, en el cine me tengo que aflojar el cinto, y al sentarme a comer. Ése es mi indicio de siempre" (16/03/63). Aún en estos pasajes es evidente que nunca pierde una forma poéticamente pulida. Ya dijo también Amícola que "La forma retóricamente bella es, pues, uno de los caminos lícitos de las A para llegar a los lectores y hacerles aceptar el reto de la lectura"(32). De este modo, la gordura de su cara es una luna llena, la soledad se junta con un trastorno estomacal, o la panza se cría. 
ensayos ${ }^{20}$. Podemos así volver a los ejemplos antes señalados para evidenciar esa presencia del yo emergiendo de modo directo.

\section{LA VOZ DE MANUEL}

La voz de Puig para los Puig. La voz emerge de esa escritura cotidiana en pos de comunicar una imagen del propio narrador a esos otros ausentes. Voz que carga con una menuda tarea: dar cuenta de un espacio-tiempo determinado, de un "estuve aquí y de este modo" y lo pongo en palabras solo para ustedes, para que sean testigos de esto que aquí se elabora. Aunque, inevitablemente, al dar cuenta de sí mismo, como esclareció Judith Butler, se está implicando ese acto en una temporalidad social determinada. El yo del narrador que se narra pone en palabras una teoría social que le excede ${ }^{21}$. Damos cuenta de nosotr@s mism@s para alguien. Hay, así, una entrega; $\mathrm{y}$, en esa desposesión está la condición de posibilidad de dar cuenta de sí a un otr@. Y, necesariamente esta forma narrativizada de dar cuenta de un@ mism@ conlleva necesariamente un grado de opacidad parcial (experiencia corporal, relaciones primarias irrecuperables, etc.) (Butler 59).

Siguiendo a Adriana Cavarero, en oposición a Nietzsche, Judith Butler aporta la idea de la vulnerabilidad de la condición humana en tanto somos seres expuestos. Por eso, argumenta, "existo para y en virtud de ti. Si he perdido las condiciones de la interpelación, si no tengo un "tú" a quien dirigirme, me he perdido a "mí misma". Cavarero sostiene que uno solo puede contar una autobiografía a otro y hacer referencia a un "yo" únicamente en relación con un "tú": sin el "tú", mi propia historia resulta imposible" (50). Manuel Puig como "Coco_" existe para sus familiares. El yo se ubica en ese apodo 17).

21 "El "yo" no está al margen de la matriz prevaleciente de normas éticas y marcos morales en conflicto. En un sentido importante, esa matriz es también la condición para la emergencia del "yo", si bien no son las normas las que lo inducen en cuanto causas. Basado en ello, no podemos concluir que el "yo" es el mero efecto o instrumento de un ethos previo o un campo de normas antagónicas o discontinuas. Cuando el "yo" procura dar cuenta de sí mismo, puede comenzar consigo, pero comprobará que ese "sí mismo" ya está implicado en una temporalidad social que excede sus propias capacidades narrativas; a decir verdad, cuando el "yo" procura dar cuenta de sí sin dejar de incluir las condiciones de su emergencia, tiene que convertirse, por fuerza, en teórico social” (Butler 18-19). 
familiar, afectuoso y cercano. Sus lectores son esos tres seres (Hermano, Padre y Madre) cuya lectura interpela a las palabras de Coco incluso antes de ser escritas. La historia personal, cotidiana, del mundo íntimo compartido allá en General Villegas y en Buenos Aires, efectúa una operación de trasvase al contexto mundial de cada espacio que Manuel visita, sea Estocolmo o New York. Así, puede utilizar aquellos elementos comunes a los suyos para hacer comparaciones, chistes, homologaciones a situaciones y personas que va conociendo a lo largo de su juventud y adultez fuera del país y fuera de ese núcleo familiar; y, por momentos, reconocer con humor algunas de sus "voces": por ejemplo, "Habló la voz que hincha" (18/07/63); "Habló Pedro Moroni" (26/07/63).

Fundamentalmente fueron esas imágenes y el lenguaje familiar -más arriba señalado- lo que se utiliza a la hora de dar cuenta de sí. También las atenciones, cuidados y preocupación por los suyos forman una porción importante del conjunto de cartas. Es un modo de estar materialmente presentes. Tanto de un lado como del otro de esta comunicación fluida hay constantes: intercambio de regalos, envío de comidas transportadas en encomiendas, envío de ropa comprada a medida para cada uno de los integrantes de la familia, etc. Pero también el lenguaje y las expresiones utilizadas construyen un determinado bagaje ideológico y de pertenencia a una clase que se concreta en diferentes momentos de este grupo de materiales.

Por eso último nos interesa señalar también el modo en que las cuestiones de la polis aparecen explicitadas en estas cartas familiares. Para lo cual arrancamos con un breve exordio: Sylvia Molloy, en su artículo "Identidades textuales femeninas: estrategias de autofiguración", pensó en la autorrepresentación marcada por el género - donde las mujeres latinoamericanas desean ocupar un sitio diferente al del varón en la cultura letrada de sus países, desafiando, así, los estereotipos culturales. En esta línea reflexiva afirmó que "Desde la época del escritor-hombre de estado, figura paradigmática del siglo XIX, la imagen del letrado latinoamericano, como figura de autoridad comprometida en las cuestiones de la polis (...) sigue vigente" (69). Ya a partir de las primeras cartas podemos observar que el joven Puig conoce el mundo político $\mathrm{y}$ tiene una fuerte posición tomada aunque su compromiso no excede lo discursivo. Hay una pertenencia de clase desde donde se posicionó a partir de un discurso mamado en el seno familiar; de hecho marca reiteradamente su preocupación por su hermano Carlos quien se muestra interesado por el comunismo y alerta a su madre sobre la situación. Aira señaló que "En las novelas de Puig el individuo se manifiesta como miembro de una familia, 
como lector y aprendiz de una lengua, en definitiva como perteneciente a la clase media argentina" (28). Es esa pertenencia de clase con su código de conductas y comportamientos específicos la que se hace presente en sus dichos sobre política dentro de esta correspondencia privada. Evidentemente, como señala Aira, Puig tuvo la capacidad de transponer esos elementos también a su escritura pública. Será desde ese posicionamiento de clase, también, en el cual se ampare para compartir con los suyos su anti-peronismo, sus críticas a Frondizi o su horror por los gobiernos comunistas en curso en esa época. Aquí algunos ejemplos:

Por la calle tuve la desgracia de ver a Perón y señora, el podrido, me produjo náusea. Ella una chirusa teñida de rubia. Yo que soñaba con un encuentro con AVA, me encuentro con Pocho hijo de puta ${ }^{22}$ (28-03-61)

(...) feliciten a Fronduro, infeliz de porquería ${ }^{23}$ (01-06-61).

En la carta del 14 de febrero de 1962, luego de visitar Rusia, responde las preguntas de su hermano dando una perspectiva personal horrorizada de lo que vio en su visita; "(...) temo parecer exagerado pero la verdad es que no encontré nada bueno". Le transcribe el fragmento de una carta recibida desde Cuba donde su amigo, Néstor Almendros, le describe la situación socio-económica (04/05/62). En otra actualiza estos datos: "Yo he hablado con mucha gente que ha ido a Moscú y las versiones son blancas o negras, según las ideas políticas del que habla. Desgraciadamente para todos esos millones de rusos la versión negra es la verdadera" (28/09/62).

Pero quizás, en el ámbito del extra-familiar lo que más se hace patente como interés de Manuel en sus cartas fue su mirada crítica sobre el mundo de la cultura. En los primeros años eran frecuentes sus críticas al escritor Mujica Láinez: "Felicitalo a Mujica Láinez iqué burro!” (02/05/58); “iQué tarado M. Láinez gustarle la de Gielgud! Todo porque es de G. Greene. Aquí los críticos la despedazaron. Y qué tarada la V. Ocampo eschancarse ${ }^{24}$ en traducirla" (08/04/58). También eran frecuentes sus críticas sobre espectáculos a los que asistía (tanto teatrales como cinematográficos). Claro que el cine

22 Se refiere a Ava Gardner que estaba viviendo en Madrid, así como J. D. Perón con María Estela Martínez de Perón.

23 Manuel señaló lo citado por la política económica de Frondizi.

24 "Esforzarse" en dialecto parmesano rural. 
tiene una importancia capital en su vida desde su temprana infancia y en sus elecciones (inicialmente viaja a Roma becado para estudiar cine y sus primeros escritos son guiones cinematográficos; luego las figuras del mundo del cine poblarán su literatura). Por momentos elogiaba enormemente a actrices y actores, así como tenía observaciones despiadadas a interpretaciones que consideró desmesuradas. Así, sus críticas sobre cine van desde lo más coloquial (Ej.:"Welles es un gran boludo" (18/07/63)); a otras más fundamentadas (Ej.: "Así que cayeron con "The Knack”, qué clavo es, yo también caí pero me fui por la mitad, qué asco, le hice la cruz a esas comedias inglesas de falsa vanguardia, son un asco y acá la crítica las pone por las nubes. Es el momento de todo lo inglés" (21/10/66)); y otras que le sirven de apoyo para explicar problemas teóricos vinculados con la creación artística $(\mathrm{Ej}$.: criticando Le feu follet (1963) de Malle sentencia: "Media soporífera, todas las finezas (...) se pierden en una catarata de explicaciones, que por qué no le gusta esto y por qué siente aquello y el personaje se explica a sí mismo durante toda la cinta en vez de que la acción se encargue de mostrarlo al público" (06/03/64)).

En este sentido son interesantes algunas reflexiones sobre el mundo de la escritura. Comentó en sus cartas familiares mucho más cantidad de espectáculos que de libros. Si bien desde la época en que inicia los trámites para publicar su primera novela se suceden muchos chismes sobre el mundo editorial y los escritores de moda, su mirada sobre libros leídos le permitió extenderse en reflexiones acerca del acto de escribir y sus problemáticas. Ej.:

Leí una colección de artículos de Roberto Arlt, "Aguafuertes Porteñas" (...) me resultó utilísimo porque hace un uso especial del lunfardo desastroso porque se complace en eso y hace uso y abuso. Me vino muy bien porque tenía mis dudas sobre eso y me decidí a corregir una cuantas expresiones. Creo que el uso tiene que limitarse a lo estrictamente necesario, cuando no hay otra palabra que ese personaje de acuerdo a su psicología pueda decir en vez de la expresión en lunfardo. Lo mismo para los argentinismos, si resultan realmente “expresivos” sí, si no, ¡no! (14/02/64).

\section{LA VOZ QUE DISIMULA: EL TEATRO DE ENTRECASA}

Siguiendo la propuesta de lectura que Derrida hace del Ecce Homo de Nietzsche, Loureiro afirmó: 
(...) lo autobiográfico no puede ser nunca autosuficiente ya que no puede darse la presencia completa del yo ante sí mismo, y si el borde entre vida y obra nos deja ver que lo autobiográfico es en verdad autográfico, el paso necesario de la firma (y la escritura del yo) a través de la oreja del otro, convierte a lo autobiográfico en heterobiográfico (7).

El recorrido de las cartas no permite en ningún momento aseverar nada respecto de la vida sentimental de Manuel, pero cotejando con otras fuentes, lo que aparece a trasluz es un disimulo constante de su identidad sexual. Se percibe un respeto por la sensibilidad de sus padres ante quienes no expresa de modo escrito nada explícito vinculado a ello.

Si bien las entrevistas que publicó Armando Almada Roche no son consideradas como fiables por su hermano Carlos, allí se nos presenta a Puig afirmando una iniciación sexual temprana donde su identidad gay aparece clara desde la pubertad. También en esas entrevistas se describe a un tal Angelo, amante italiano de Puig cuando apenas llegó a Roma ${ }^{25}$. Según este periodista la descripción de Manuel de sus vivencias sexuales de juventud versaban así:

Fueron años muy duros, llenos de tristeza también. En mis tiempos era muy duro levantar un tipo en la calle. Estaba la policía para reprimirte. La sociedad te vigilaba y marginaba ferozmente. A veces los tipos que levantabas terminaban robándote y moliéndote a palos. (...) El riesgo que corría un homosexual en los años sesenta era muy grande. Teníamos que vivir escondidos reprimiendo nuestra sexualidad, fingiendo hasta con los amigos (98).

Según su amiga y biógrafa, Suzanne Jill Levine, a la vuelta de su primer periplo europeo Manuel intentó hablar de su identidad sexual con sus familiares más allegados, pero no quisieron escucharlo demasiado. En la entrevista con Almada Roche, Manuel afirmó: "Todos los padres, al principio, a pesar de aceptar la condición de sus hijos, se sienten frustrados. Yo creo que la

25 "En mi primer viaje a Italia conocí a Angelo, un muchacho de 30 años, un adonis. Me enamoré de él, de ese país. Italia era entonces, y sin duda aún lo es, un paraíso en que las prostitutas y los homosexuales de todas partes del mundo alquilaban o compraban a una mujer, un joven, un hombre o un travesti. Al principio no me di cuenta de su carácter extraño ni de su belleza. (...) Me enamoré de Angelo y sufrí mucho” (Almada Roche 77). 
frustración y el dolor son más grandes para ellos al saber que la sociedad va a desplazar y marginar a sus hijos" (138).

Traemos estas informaciones para volver a los textos de las cartas familiares con otra perspectiva: los amigos más íntimos de Manuel compartían mucho más que sus intereses culturales, también había historias de vida similares de distancia respecto a los valores sociales establecidos y heteronormativos. Así, la presencia constante de Mario Fenelli en las cartas se explica porque la amistad entre ambos nació de un encuentro de dos seres despojados, necesitados de afecto y con similitudes en sus capacidades intelectuales. Levine describe la situación de este modo:

(...) aunque Manuel y Mario se sentían atraídos desde el momento en que se conocieron (al parecer Manuel estaba más encaprichado que Mario) no se convirtieron en amantes sino, como lo expresó Manuel, en "hermanas" que compartían las penas de amor, que se reían del mundo juntas. Se respetaban profundamente cada uno la inteligencia del otro y se deleitaban mutuamente en la compañía del otro (98).

Pero en las cartas familiares no aparecen datos tan claros sobre esto. Sí la presencia de Mario es constante como un amigo cuya opinión sobre la escritura de Manuel será siempre capital.

Las menciones a situaciones de seducción en las que se ve implicado son escasas en las numerosas cartas a su familia. Una excepción es cuando narra un encuentro con una actriz francesa de origen argelino considerada como una de las más sexys de su época:

Ahora una pequeña escurya ${ }^{26}$, pero esto sí, que no salga de ustedes tres porque no me va a hacer ninguna gracia lo contrario: en París tuve un romance pasajero y "maudit" sin ninguna consecuencia con Françoise Arnoul. ¿Se desmayaron? (12-06-59).

Si bien podemos imaginar que como afirma su biógrafa: "Ingenioso y apuesto, Manuel era irresistible para la mujeres, a quienes les gustaba pensar que podían convertirlo" (Levine 85), no deja de ser destacable esta necesidad de disimulo y recato del hijo para con sus padres. A su vez es muy comprensible ese comportamiento en el contexto de la época. 
A pesar de todo ello, su disimulo de las cartas familiares, por fortuna, no era similar en su vida diaria ni en su producción literaria. Según afirma Jill Levine, por ejemplo,

La homofobia que Coco sobrellevaba de joven en Buenos Aires figuraría de modo destacado en su tercera novela, The Buenos Aires Affair. La trama saltaba los años 50 -correspondientes a la carrera temprana y la historia sexual de Manuel- y seguía a través de la agitación política de fines de los 60 y principios de los 70 (82-83).

Esto no quiere decir que su producción fuera enteramente autobiográfica ni mucho menos. Tampoco le quita potencia que algunos elementos en efecto lo fueran ${ }^{27}$. Lo que ensalza su talento es la capacidad de transformar situaciones vinculadas con la sexualidad humana en su espectro más amplio en metáforas de otras situaciones socio-políticas. Así, Levine analizando sus novelas puede señalar que "A través de la relación sadomasoquista de sus personajes Leo y Gladys, alter egos masculino y femenino de Manuel, psicoanalizaría el nudo inextricable del fascismo argentino y la represión sexual" (83).

Valga sobre este apartado la aclaración que nuestra intención no es definir en una identidad fija y estable. Justamente fue él un autor que en su producción cuestionó los lugares de fijeza de las identidades. Pero sí nos pareció necesario destacar esta operación de disimulo u ocultamiento, un teatro de entrecasa para espiar desde el clóset.

Por último, siguiendo a Susanna Egan, Amícola afirma que "cada vida está, por cierto, llena de conflictos y lo que una A logra, en definitiva, tiene que ver con lo que se podría llamar un "mito explicativo" de esa vida" (125). De algún modo esa era la tarea propuesta por este escrito: acceder desde los materiales presentes a ese mito explicativo de su propia vida que Manuel construyó para la mirada familiar. Des-andar esas huellas en tinta que durante años trazaron un camino de su periplo por diferentes ciudades del mundo. Esas huellas que Regine Robin vincula en su propuesta teórica de este modo:

$27 \quad$ Sobre The Buenos Aires Affair, Levine describe lo siguiente: "El encuentro de Leo con el homosexual sin nombre fue no sólo forraje para las páginas policiales: fue la fábrica definitiva que a la vez aterrorizaba y fascinaba a Manuel atraído, a los 20 años, a citas riesgosas en los ómnibus y las calles recorridas por la policía de Buenos Aires. Manuel era una "gran reina" atraída por el sexo anal y los hombres duros de penes grandes: obsesión descrita en gráfico detalle en The Buenos Aires Affair" (83). 
Escritura trabajo de duelo, a la vez de deconstrucción de la ilusión biográfica y de reconstrucción, elaboración de un lugar distinto no aleatorio, lugar de verdad. Esta sería la tarea imposible de este objeto inasible que es la autoficción. Ni autobiografía, ni biotexto, ni museo portátil, ni heteronimia radical, sino elaboración de una huella que se transformó en palabra de verdad (57).

\section{CONCLUSIONES}

El recorrido que hicimos en este escrito partió de las cartas que escribió Manuel Puig para su familia. Vimos que la construcción de un relato de su cotidianidad para los suyos fue lo que signó el desarrollo de las mismas a lo largo de los años. Pudimos observar que el lenguaje desarrollado al interior de la familia -principalmente por la influencia de la rama materna (Delledonne)se mantiene y desarrolla durante todo los años que ese intercambio se extiende (1956-1983). Es un intercambio fructífero en el que fundamentalmente la voz de Manuel y la voz de la madre se hacen eco y por momentos se hacen uno. Manuel imita a Male. El estilo del escritor tiene mucho de ese diálogo de madre e hijo en una lactancia estirada virtualmente en el tiempo.

Se pudo visualizar una relación muy cercana donde los detalles más nimios constituyen lo central dejando en sombras aquello de lo que se evita hablar. Pudimos describir algunas estrategias de disimulo para dejar la sexualidad en sombras al menos dentro de ese ámbito casero de la correspondencia privada del escritor. Si bien esto no lo hacía el joven Manuel en la correspondencia con sus amigos y amigas ni en su escritura pública, sí lo mantenía al interior de estas cartas.

Las bondades de los buenos intercambios, una sucesión de correspondencia que mantiene viva la llama de un diálogo ininterrumpido. Pudimos delinear algunas de las estrategias de Manuel para auto-representarse. Elige seguir llamándose Coco para los suyos. A pesar de los viajes, de la fama, de sus elecciones de vida, sigue aceptando ese lugar que le otorga el apodo íntimo. En las cartas sostiene y desarrolla el humor propio de la familia, y se reserva un humor más corrosivo y revelador de su identidad para las cartas con sus amigos o para ponerlo en boca de personajes como el de Molina en El beso de la mujer araña ${ }^{28}$. 
Molina: Pero qué lindo cuando una pareja se quiere toda la vida. VALENTín: ¿A vos te gustaría eso?

Molina: Es mi sueño (...)

VALENTín: En el fondo sos un señor burgués

Molina: Una señora burguesa

VALENTín: Si fueras mujer, no querrías eso.

MoLina: Lo único que querría es vivir al lado de un hombre maravilloso toda la vida (Puig 33).

\section{FUENTES}

Puig, Manuel. Querida Familia: Tomo 1. Cartas europeas (1956-1962). Buenos Aires: Entropía, 2005.

Querida Familia: Tomo 2. Cartas americanas. New York - Río (1963-1983). Buenos Aires: Entropía, 2006.

\section{BIBLIOGRAFÍA}

Aira, César. "El sultán”. Paradoxa. Literatura y filosofía 6 (1991): 27-29.

Almada Roche, Armando. Buenos Aires, cúando será el día que me quieras: conversaciones con Manuel Puig. Buenos Aires: Ed. Vinciguerra, 1992.

Amícola, José. Autobiografia como autofiguración. Estrategias discursivas del yo y cuestiones de género. Rosario: Beatriz Viterbo editora, 2008.

Arfuch, Leonor. El espacio biográfico. Dilemas de la subjetividad contemporánea. Buenos Aires: Fondo de Cultura Económica, 2002.

Borinsky, Alicia. "Manuel Puig: Vida propia/Historias ajenas". Autobiografía y escritura. Comp. Juan Orbe. Buenos Aires: Corregidor, 1994. 41-55.

Butler, Judith. Dar cuenta de sí mismo. Violencia ética y responsabilidad. Buenos Aires: Amorrortu, 2009.

Catelli, Nora. El espacio autobiográfico. Barcelona: Lumen, 1991.

Cixous, Helene. "La venida de la escritura". Feminaria 4 (1989 noviembre): 22-28.

De Man, Paul. "La autobiografía como desfiguración”. La autobiografia y sus problemas teóricos, Suplementos Anthropos (29). Comp. Ángel Loureiro, Barcelona: editorial Anthropos, 1991. 113-118

Derrida, Jacques. "Firma, acontecimiento y contexto". Márgenes de la filosofia. Madrid: Cátedra, 1994.

Otobiografías. La enseñanza de Nietzsche y la política del nombre propio. Buenos Aires: Amorrortu, 2009. 
Echavarren, Roberto. "Identidad versus vapor". Encuentro Internacional Manuel Puig. Compiladores J. Amícola y G. Speranza, Rosario: Betriz Viterbo, 1998. 245-258.

Friera, Silvina. "Aquellas cartas desde Europa". Página 12. Buenos Aires (12 de julio de 2005) http://www.pagina12.com.ar/diario/cultura/subnotas/53560-17935-2005-07-12.html

"El escritor que escapó del canon”. Página 12. Buenos Aires (12 de julio del 2005) http://www.pagina12.com.ar/diario/cultura/7-53560-2005-07-12.html

Goldchluk, Graciela. "Exilio y travestismo, los escritos mexicanos de Puig". Sexualidad y nación. Ed. Daniel Balderston. Pittsburgh: Biblioteca de América, 2000. 153-171

Kristeva, Julia. "Stabat Mater". Historias de Amor. Buenos Aires: Siglo XXI ed., 1988: 209- 231

Lejeune, Philippe. "El Pacto autobiográfico". La autobiografia y sus problemas teóricos. Suplementos Anthropos (29). Comp. Ángel Loureiro, Barcelona: editorial Anthropos, 1991. 47-61

Levine, Suzanne Jill. Manuel Puig y la mujer araña. Buenos Aires: Seix Barral, 2002.

Loureiro, Ángel. "Problemas teóricos de la autobiografía". La autobiografia y sus problemas teóricos. Suplementos Anthropos (29). Comp. Ángel Loureiro, Barcelona: editorial Anthropos, 1991. 2-8

Marcantonio, Carla. "A ella se le ve que algo raro tiene, que no es una mujer como todas: El melodrama como cine queer en Manuel Puig”. Otras historias de amor. Comp. Adrián Melo. Buenos Aires: Lea, 2008. 31-43.

Manrique, Jaime. Maricones eminentes. Arenas, Lorca, Puig y yo. Madrid: Síntesis, 2000.

Molloy, Sylvia. "Identidades textuales femeninas: estrategias de autofiguración". Mora 12 (diciembre 2006). 68-86

Perlongher, Néstor. “Breteles para Puig”. Prosa Plebeya. Buenos Aires: Colihue, 2008. 127-129.

Puig, Manuel. Teatro Reunido. Buenos Aires: Entropía, 2009.

Robin, Regine. "La autoficción. El sujeto siempre en falta". Identidades, sujetos y subjetividades. Comp. Leonor Arfuch. Buenos Aires: Prometeo Libros, 2005.45-58.

Sarlo, Beatriz. "El brillo, la parodia, Hollywood y la modestia (1990)". Escritos sobre literatura argentina. Buenos Aires: Siglo XXI, 2007. 323-324.

Sarlo, Beatriz. “¿Pornografía of fashion? (2005)”. Escritos sobre literatura argentina. Buenos Aires: Siglo XXI, 2007. 462-470.

Saítta, Sylvia. "Manuel Puig, Querida familia: Tomo 1. Cartas europeas (1956-1962)". Orbis Tertius.12. (2006). http://www.orbistertius.unlp.edu.ar/numeros/numero-12/saitta.pdf

Vivancos Pérez, Ricardo F. "Una lectura queer de Manuel Puig: Blood and sand en La traición de Rita Hayworth". Revista Iberoamericana 215-216 (abril-septiembre 2006). 633-650

\section{ENTREVISTAS}

“Entrevista a Fondo - Manuel Puig”, entrevistado por Joaquín Soler Serrano para el programa de televisión española "A fondo" (TVE), 1977. 